Title:

Becoming Empowered: a grounded theory study of Aboriginal women's agency

Name \& Qualifications:

Roxanne Bainbridge: BSocSc (Hons 1), PhD

\title{
Position Title:
}

Senior Research Officer

Empowerment Research Program

\section{Affiliation:}

The School of Education and The Cairns Institute

\section{Postal Address:}

Roxanne Bainbridge

The Cairns Institute

James Cook University

PO Box 6811

Cairns Q 4870

Australia

Email: roxanne.bainbridge@jcu.edu.au

Telephone: 0740421710

Fax: 0740421880 


\section{Abstract:}

Objective: The study aim was to identify the process underlying the performance of agency for urban-dwelling Aboriginal women in contemporary Australian society with a view to promoting social change for Aboriginal people.

Method: Grounded theory methods were used in the conduct of twenty life history narrative interviews with Aboriginal women from across fourteen different language groups.

Results: Analysis identified a specific ecological model of Aboriginal women's empowerment, defined as "Becoming Empowered". "Performing Aboriginality" was identified as the core category and encompassed the women's concern for carving out a fulfilling life and carrying out their perceived responsibilities as Aboriginal women.

Conclusion: While confirming much of the extant literature on empowerment, the analysis also offered unique contributions - a spiritual sensibility, cultural competence and an ethics of care and morality. This sheds new light on the creative ways in which Aboriginal women 'disrupt' discourses and create alternate modes of existence. The findings have implications for improving quality of life for Aboriginal people by informing the practical development and delivery of social and health policies and programs.

Key words: Aboriginal; Women; Agency; Empowerment; Grounded Theory 
In Australia, the failure of many, including successive governments, to address for social change in a holistic way - through material, human and intellectual resources - has negated attempts of producing sustainable change for Aboriginal people. While material resources are critical, evidence shows that the availability of, and access to these resources alone, does not always correlate with greater control, and often incurs little actual influence on social outcomes and practice [1]. So what is missing; what enables the uptake of programs and such whether or not they are well-funded, socially inclusive and/or culturally sensitive? This paper responds to that question; it identifies the process underlying the performance of agency for urban-dwelling Aboriginal women to understand what is required to assist others, less fortunate, to become self-directing and ultimately garner the skills to change the circumstances of their existence.

\section{Why Agency?}

For many Aboriginal people, the limitation of life potential, survival, is transgenerational and embedded in the usurping of control through the continuing processes of colonisation. While self-determination is not the panacea for all social ills endured by Aboriginal people; it is the foundational work that is required for individuals to move forward. But what does this process look like for Aboriginal people? Reflecting on my narratives of survival and how I moved beyond, I considered the concept of agency.

Resources alone will not necessarily bring about change unless individuals are able to recognise and utilise those resources in their own best interests. As part of his proposal on social reform, Sen [2] supports the centrality of individual agency to achieve the reality of social change for those experiencing disadvantaged conditions. Sen also argues that when people have knowledge, skills and resources, they will act in their own best interests.

What do we mean by agency? Agency is about the individual's capacity to differ from, rather than replicate social discourses and engage as significant actors in that process [3; 4]. Davies [4] explains:

"[...] having access to a subject position in which they have the right to speak and be heard $[. .$.$] as author of their own multiple meanings and desires [...] as having a$ sense of oneself as one who can go beyond the given meaning in any discourse and forge something new from a combination of previously unrelated discourses, through the invention of words and concepts that capture a shift in consciousness that is beginning to occur, or through imagining not what is, but what might be” (pp. 66-67)

While substantial personal change is invoked by repositioning self within new discourses, individuals also experience a degree of resistance between belief and everyday practice. This is why it is critical to understand the strategies orchestrated by those Aboriginal people who have transitioned this process within the bounds of colonisation and patriarchy (women) and further understand how notions of self, power and discourse are implicated in change processes.

\section{Aim}

The objectives of the study were to: 
- Identify the process and dimensions underlying Aboriginal women's performance of agency - the facilitating environments, actualisation and outcomes of agency; and

- Develop a substantive theory of the process.

\section{Methods}

The voices of twenty Aboriginal women from across Australia, (see Table 1) embodied the spirit of this investigative journey. To document meaning across time, data was generated through the conduct of face-to-face life-history narrative interviews. As an Aboriginal woman sharing a similar subject position to that of my participants, and myself a participant in the study, I was certain to bring biases to the study. As much as possible, I wanted to avoid imposing a predetermined framework on the knowledge shared, and so used grounded theory methods to keep the analysis close to the data. A process of concurrent theoretical sampling, data collection and constant comparative analysis, characteristic of grounded theory methods was adopted. It enabled explication of all constituent elements of the research phenomenon as well as their interrelationships.

Table 1: Participant demographics

\begin{tabular}{|c|c|}
\hline Characteristics & No. \\
\hline \multicolumn{2}{|l|}{ Age } \\
\hline $18-34$ & 5 \\
\hline $35-54$ & 12 \\
\hline $55+$ & 3 \\
\hline \multicolumn{2}{|l|}{ Highest Education Level } \\
\hline Year 10 or less & 2 \\
\hline Year 12 or TAFE & 6 \\
\hline University degree & 12 \\
\hline Currently Studying & 16 \\
\hline Children & 17 \\
\hline First language English & 20 \\
\hline Speak language & 1 \\
\hline Paid work & 17 \\
\hline Board position & 7 \\
\hline
\end{tabular}

\section{Results}

The basic social psychological process identified in the women's narratives, "Becoming Empowered", was negotiated through retrospective mechanisms, and in interactions between self and others, self and history and self and their environment. In turn, this led to the exercise of personal agency. Being Aboriginal infused the lifeworld of the women with meaning and strengthened their life purpose; "Performing Aboriginality" was thus conceptually identified as the constant influencing background for the women - their core concern for carving out a fulfilling life and carrying out their perceived responsibilities as Aboriginal women. 
Glaser's [5] causal-consequence model was adapted to identify what the process looked like the causes, conditions, strategies and consequences. It depicted four facets, Defining Moments, Seeking Authenticity, Authoring Narratives of Self and Capturing Autonomy (See Figure 1). The process was not a seamless transition and best illustrated as a dynamic, experiential, fluid, open process of becoming - a reiterative spiral from which entry and exits may be made at differing points and in which transgression, progression and regression occurs. It was non-linear; facets overlapped and replicated throughout the life course at various intensities; and variously, some facets and/or their components were omitted.

\section{Figure 1: Process of "Becoming Empowered"}

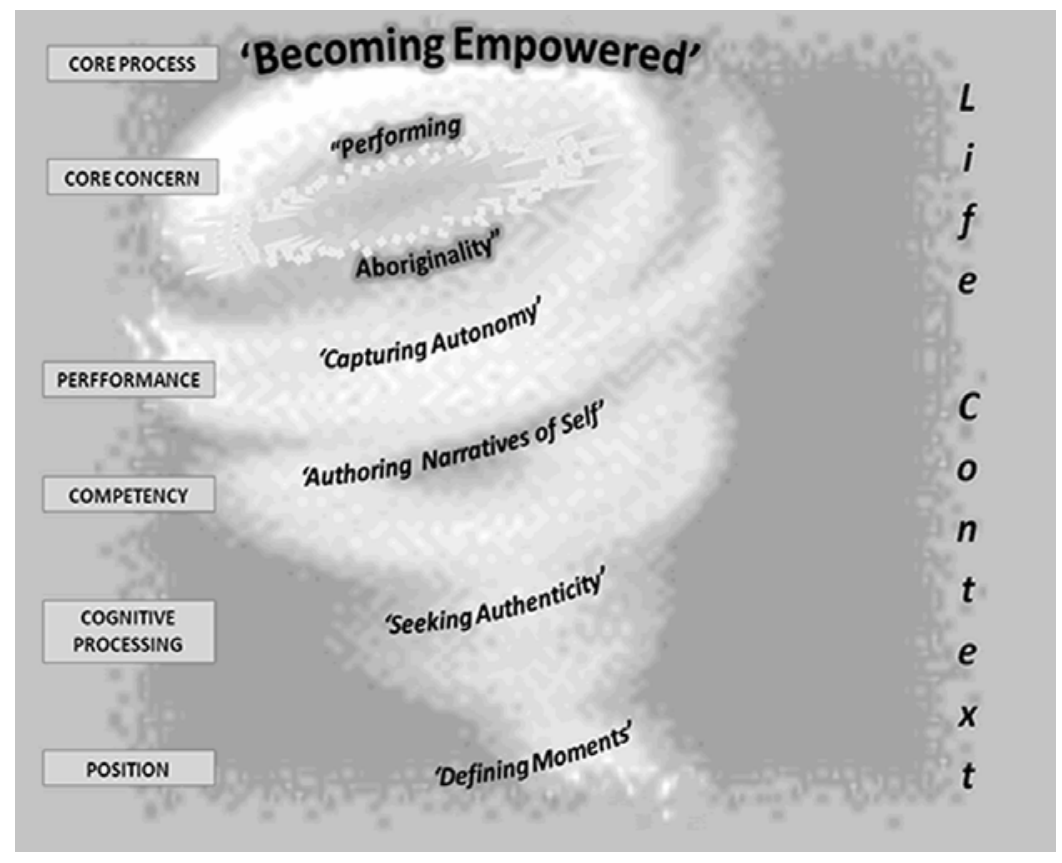

\section{Voices: 'Defining Moments'}

The process of "Becoming Empowered" was initiated through critical junctures in life that were transformational - 'Defining Moments'. These times challenged the women's sense of self and ways of being in the world for example, challenges to their worldviews, self-identity, gender roles, sense of belonging, ethnicity and so on. This initiated a need to construct and negotiate new realities, and new ways of knowing, being and doing to position themselves in relation to their redefined realities. For example, following the passing of her Mother, one participant related "I had to change everything around, how I am goin' to cope with it, what am I going to do, who am I goin' to come up against” Shae.

\section{'Seeking Authenticity'}

'Seeking Authenticity' embodied a spiritual sensibility and was characterised by formal and informal mentoring relationships, opportunistic observations of behaviours, role modelling and past memories. The mediating role of developing a critical, moral and ethnic consciousness and identity formation and agency was also apparent. It is similar to Freire's 
[6] concept of conscientisation or critical consciousness, which he considered key in realising empowerment. Bree's narrative provided a powerful example:

"And othering, as I said, I had to reassess who I was, and it was looking at yourself through the perceptions of others eyes, and that was quite, not an easy thing for me to do...because you know what, that's given me my grounding now, first and foremost I will always be Aboriginal”.

This facet also evidenced an exploration of ethnicity and the women's aspirations to embody moral authority in their daily lives. Aboriginality carried a core meaning as the anchor for identity work and the women's sense of agency. For example, Meghan said "you know my Aboriginality has been my guiding force right from the beginning”.

\section{'Authoring Narratives of Self'}

'Authoring Narratives of Self' revealed how the women strategically positioned themselves to sustain a desirable quality of life and assume their roles as Aboriginal women. They expressed a genuine moral concern for others and became defenders of humane values, social justice and moral correctness and reached out beyond their more immediate social relations and structures. While this ethics of care and responsibility prioritised an allegiance to Aboriginal people, it also encompassed humankind and the environment. The women made frequent references to their roles and responsibilities as Aboriginal women, such as: "looking after the community wellness" Meghan. They sought harmony by standing in relatedness to others, cultivating belonging, maintaining relationships, resolving problems and ensuring cultural continuity. Family was a powerful resource and central support for all women.

\section{'Capturing Autonomy'}

'Capturing Autonomy', involved the application of knowledge and skills developed previously. It was characterised by varying degrees of autonomy, liberation and selfdetermination including the ability to name and be self-directing - exercising agency. The women assumed leadership and advocacy roles; care and promoting the empowerment of others was central to their ways of operating in the world. They created and accessed spaces which allowed the development of their personal, social and political judgement in regards to personally relevant aspects of life. Motivation, competence, speaking out, breaking cycles, making choices, working to liberate self and others and renewing being were prominent. Amanda notes the significance of breaking cycles: "I'm the first generation in my family that can say at 20 years of age that I have complete control over my life".

\section{Conclusion}

The process showed that agency relates to the ability of women to participate in the change process through choice and as significant actors [3; 4]. Consistent with Kabeer's [7] theorising, agency is more than observable action; it also relates to "the meaning, motivation and purpose” (p. 438) individuals attach to their exercise of agency; in this case Aboriginality and the desire for a better life for self and community. Conceptualised as an ecological model of empowerment, (Figure 2) it showed the interconnectedness of resources, agency and achievements framed by the notion of 'choice'. The energies or power to make decisions and act, emanate from within and with others (agency) and are derived from human and social capital (resources). Importantly, resources drawn upon were not only material resources; 
human and social resources also came into play. Achievements indicate the outcomes of the change process, which in turn feed back as resources. Each cycle serves to increase the women's resources, capabilities and effectiveness to act by expanding the availability and possibility of choice. In turn, opportunities to move from social exclusion to social inclusion are enhanced.

\section{Figure 2: Ecological Model of Empowerment}

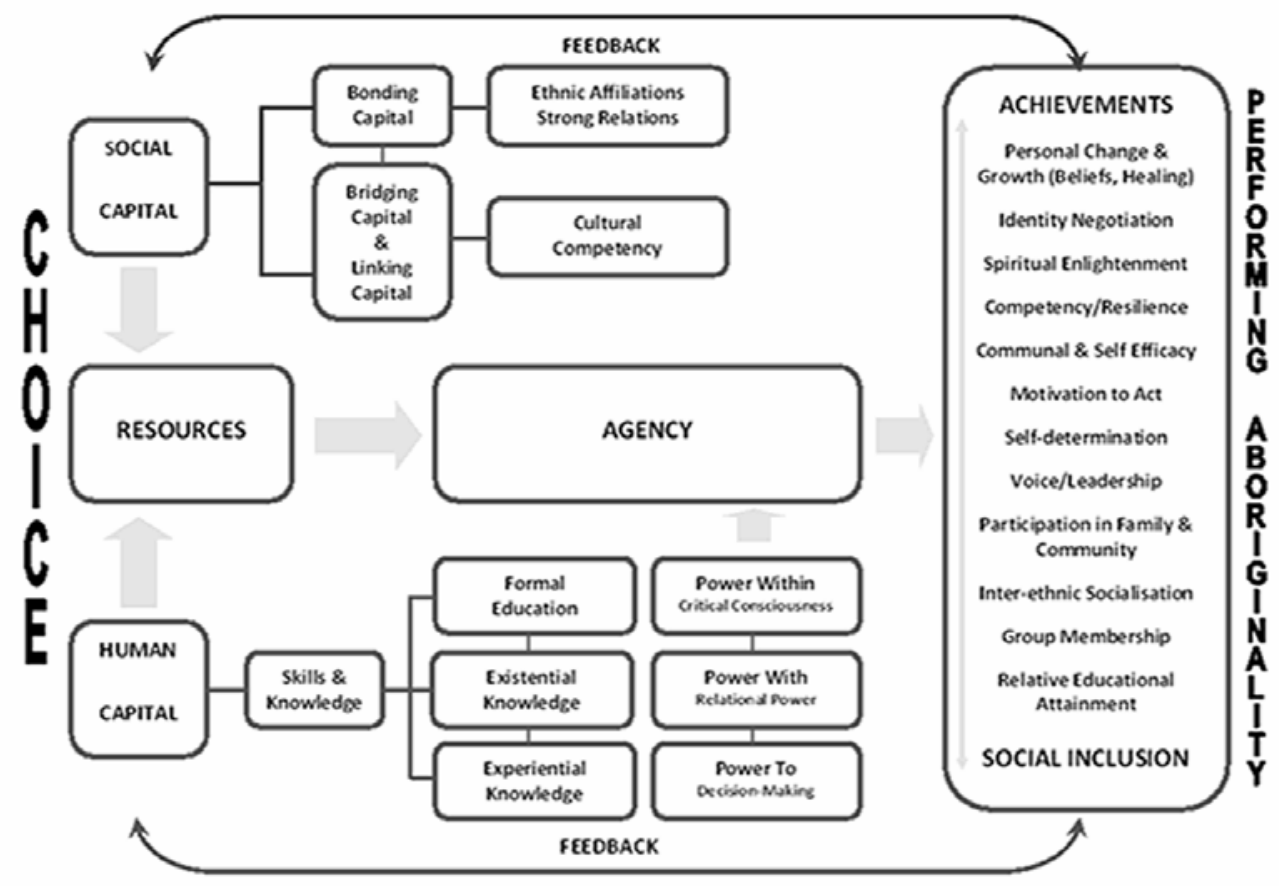

Much of the empowerment literature was confirmed. However, this process was distinguished from other models by an underlying spiritual sensibility, an ethics of morality and the notion of cultural competence. Considerable scope for further exploration lies here. The process suggested how transformational change can occur in the everyday to move beyond survival. The findings have implications for improving quality of life by informing the development and delivery of social and health policies and programs that speak to Aboriginal needs and ways of knowing, doing and being. Understanding the process can also inform how people working in an Aboriginal context, such as policy-makers, program developers and those working in the helping professions, can improve professional practice and importantly consider the role empowerment plays in health and wellbeing and in facilitating the uptake of programs and opportunities.

\section{Acknowledgements:}

I wish to express appreciation and gratitude to all the beautiful strong Aboriginal women who shared their stories and offered their time to make this study possible.

Appreciation also goes to my supervisors Professor Komla Tsey and Dr Susan Rees. 


\section{References:}

[1] Malhotra A, Schuler SR, Boender C. Measuring women's empowerment as a variable in international development. World Bank Workshop. Washington, DC: World Bank, 2002.

[2] Sen AK. Development as freedom. Oxford: Oxford University Press, 1999.

[3] Butler JP. Gender trouble : feminism and the subversion of identity. New York: Routledge, 1999.

[4] Davies B. A body of writing, 1990-1999. Walnut Creek: AltaMira Press, 2000.

[5] Glaser BG. Theoretical sensitivity: advances in the methodology of grounded theory. Mill Valley, Calif.: Sociology Press, 1978.

[6] Freire P. Education for critical consciousness. New York: Seabury Press, 1973.

[7] Kabeer N. Resources, agency, achievements: reflections on the measurement of women's empowerment. Development and Change. 1999;30:435-64. 